\title{
Thermally Stimulated Current Study of Poly(vinyl chloride)/ Poly(ethylene-co-methyl methacrylate) Blends
}

\author{
Shian-Ing CHEN and Chao-Cheng YANG* \\ New Materials $R \& R$ Department, China Steel Corporation, \\ Hsiao-Kang, Kaohsiung, Taiwan 81233, Republic of China \\ * Department of Humanities, National Yunlin Institute of Technology, \\ 123 University Road, Section 3, Touliu, Yunlin 640, Taiwan, ROC
}

(Received January 8, 1993)

\begin{abstract}
Blends of poly(vinyl chloride) (PVC) and poly(ethylene-co-methyl methacrylate) (PEMMA) were prepared by solution blending in tetrahydrofuran (THF) and studied by Thermally Stimulated Current (TSC) measurements together with relaxation map analysis (RMA). Each of the TSC global spectra of these blends exhibited three peaks where the intermediate was found generated by space charge. The high temperature peak near $70^{\circ} \mathrm{C}$ was attributed to the glass transition $\left(T_{\mathrm{g}}\right)$ of PVC-rich phase and the low temperature peak in the range of -70 to $-40^{\circ} \mathrm{C}$ was related to the $T_{\mathrm{g}}$ of PEMMA-rich phase. The significant shift of the low temperature peak from $T_{\mathrm{g}}\left(=-36^{\circ} \mathrm{C}\right)$ of PEMMA was attributed to the interaction of $\beta$-transition of PVC with $\alpha$-transition of PEMMA. Maximum interaction was also found at an PEMMA content of $20 \mathrm{wt} \%$. Arrhenius lines in the RMA of the low temperature peak were found to intersect at a single compensation point. From which the critical temperature $\left(T_{\mathrm{c}}\right)$, the relaxation time $\left(\tau_{\mathrm{c}}\right)$ and the degree-of-disorder of the polymer blends were obtained.

KEY WORDS Thermally Stimulated Current / Relaxation Map Analysis /

Poly(vinyl chloride) / Poly(ethylene-co-methyl methacrylate) / Compensation

Point /
\end{abstract}

The incorporation of other polymers into poly(vinyl chloride) (PVC) to improve physical properties has been long practiced. ${ }^{1,2}$ In a report published by Nakamura et al., ${ }^{3}$ PVC was shown to be immiscible with polyethylene (PE). However, by crosslinking at the interface of these two polymers using a dithiol as the crosslinking agent, phase dispersion and interfacial adhesion may be improved. In another report by Busscher et al., ${ }^{4}$ mechanical blends of PVC and atactic poly(methyl methacrylate) (PMMA) were shown homogeneous when PMMA content was less than $60 \mathrm{wt} \%$. When PMMA content exceeded $60 \mathrm{wt} \%$, the system became heterogeneous. Differential scanning calorimetry (DSC) results ${ }^{5}$ reported by Tremblay et al. showed that PVC is miscible with PMMA in the range of PVC content up to
$54 \%$. The miscibility of PVC with ethyleneethyl acrylate-carbon monoxide terpolymers was studied by Robeson et al. $^{6}$ by means of dynamic mechanical measurements. Their results indicated the two to be miscible although PVC and poly(ethylene-co-ethyl acrylate) are immiscible. The improved miscibility by the incorporation of carbon monoxide into the copolymer is attributed to the specific interactions between the ketone carbonyl of the terpolymer and tertiary hydrogen of PVC.

In this report, the miscibility of PVC with poly(ethylene-co-methyl methacrylate) is studied by a combination of thermally stimulated current measurements and relaxation map analysis. 


\section{EXPERIMENTAL}

\section{Materials}

Additive-free PVC was supplied by Formosa Plastics Co. (Kaohsiumg, Taiwan). Molecular weight was determined by gel permeation chromatography (GPC) as the weight-average molecular weight $M_{w}=107700$ and numberaverage molecular weight $M_{n}=65900$. Poly(ethylene-co-methyl methacrylate) (PEMMA) material was purchased from Sumitomo Chemical Co. (Japan), (trade name, Acryft WM4011). It is a random copolymer of ethylene and methyl methacrylate (MMA) with MMA content of $38 \mathrm{wt} \%$. The melting temperature was $53^{\circ} \mathrm{C}$ as determined by DSC. The molecular weights were $M_{w}=138300$ and $M_{n}=$ 71600 as determined by GPC.

\section{Gel Permeation Chromatography (GPC)}

The instrument used was Waters Maxima 820 equipped with a 410 Differential Refractometer. Three Ultrastyregel ${ }^{\circledR}$ columns were connected consecutively. The calibration curve of polystyrene standard molecular weights was obtained using tetrahydrofuran (THF) as the carrier solvent at a flow rate of $1 \mathrm{ml} \mathrm{min}^{-1}$. The molecular weight of the samples was measured under the same conditions.

\section{Blend Preparation}

$50 \mathrm{ml}$ of THF were poured into a $100 \mathrm{ml}$ flask, then PEMMA and PVC were added to prepare a $10 \mathrm{wt} \%$ solution. The polymer blend so prepared was termed as VM and showed the weight percent of PEMMA content in the system by the number $5,10,20,30,40$, and 80 following VM. The solution was stirred vigorously overnight. Films of the blends were cast onto a Teflon sheet and dried in vacuo at $80^{\circ} \mathrm{C}$. Each homopolymer of PVC and PEMMA is soluble in THF, however, most of the ternary solutions show phase separation when stocked for a long time. For PEMMA/PVC/THF ternary systems, the systems of VM80 and VM40 showed phase separation soon after stirring stop, while it took more than two weeks to observe the phase separation for the mixture including VM5, VM10, VM20, and VM30. For the sake of consistency, the solid films cast right after the solution was made.

\section{Thermally Stimulated Current}

A thermally stimulated current spectrometer (Solomat TSC/RMA model 41000, Solomat Instrument Co., Connecticut, USA) was used. The sample was polarized at 200 to $800 \mathrm{kV} \mathrm{m}^{-1}$ for $2 \mathrm{~min}$ at a temperature higher than the $\alpha$-transition. Then, it was cooled quickly to a temperature $T_{\mathrm{o}}$ to freeze the oriented dipoles. After the sample was kept for $2 \mathrm{~min}$ at $T_{\mathrm{o}}$ to make it equilibrated, the current due to dipole relaxation was measured using a picoammeter at a heating rate of $7^{\circ} \mathrm{C} \mathrm{min}{ }^{-1}$.

Sample thickness was approximately 0.05 $\mathrm{mm}$. The sample was doped with silver lacquer on both sides (each $c a .12 .7 \mathrm{~mm}^{2}$ ) and connected to the electrodes with cupper wires. Before measurement, sample assembly was evacuated to $10^{-4} \mathrm{mbar}$ and shielded with a Faraday cage.

\section{Relaxation Map Analysis (RMA)}

The sample was polarized at poling temperature $T_{\mathrm{p}}$ for $2 \mathrm{~min}$ with a poling field $E_{\mathrm{p}}$ of $200 \mathrm{kV} \mathrm{m}^{-1}$. The voltage was cut off during a hyperbolic cooling to a temperature 5 or $10^{\circ} \mathrm{C}$ below $T_{\mathrm{p}}$ for $2 \mathrm{~min}$, and then to $40^{\circ} \mathrm{C}$ below $T_{\mathrm{p}}$ at a cooling rate of $20^{\circ} \mathrm{C} \mathrm{min}^{-1}$. The relaxation spectrum was measured at a heating rate of $7^{\circ} \mathrm{C} \mathrm{min}^{-1}$ to a temperature $40^{\circ} \mathrm{C}$ above $T_{\mathrm{p}}$. All samples, except VM80, were annealed at $100^{\circ} \mathrm{C}$ for $5 \mathrm{~min}$ to let them have the same thermal history. The VM80 sample was studied without annealing. In RMA, global TSC spectra were divided into elementary spectra, each confined to a limited temperature range. Assuming that each elementary spectrum is a single Debye relaxation, then activation energy can be calculated from the Arrhenius plot of the relaxation time $\tau$. It is often observed that several Arrhenius lines intersect at one point, 
the compensation point, which is characteristic of an amorphous polymer or amorphous region in a semi-crystalline polymer. For each Arrhenius plot, the enthalpy of activation $(\Delta H)$ and the entropy of activation $(\Delta S)$ can be determined. One can define the degree-ofdisorder (DOD) number as the extrapolated value of $\Delta S$ at $\Delta H=0$. For the sake of convenience, the value is shifted by $100 \mathrm{cal} \mathrm{K}^{-1}$, to make all numbers positive. Thus, one may calculate DOD (in cal $\mathrm{K}^{-1}$ ) number from coordinates of the compensation point according to

$$
\left.\mathrm{DOD}=100-2\left[\ln \left(T_{\mathrm{c}} \tau_{\mathrm{c}}\right)+23.76\right)\right]
$$

$T_{\mathrm{c}}$ and $\tau_{\mathrm{c}}$ are denoted as the critical temperature and relaxation time at the compensation point, respectively. This DOD number may be used to reflect the degree of compatibility of a blend or the morphology between the two phase of a block copolymer. ${ }^{7}$

\section{RESULTS AND DISCUSSION}

\section{TSC Global Spectra \\ Homopolymers}

In Figure 1(a) is plotted the TSC spectrum of PVC polarized at $75^{\circ} \mathrm{C}$ in a de field of strength of $200 \mathrm{kV} \mathrm{m}^{-1}$ and measured from -150 to $100^{\circ} \mathrm{C}$ at a heating rate of $7^{\circ} \mathrm{C} \mathrm{min}^{-1}$. In order to obtain an equilibrium thermal history of these samples, materials were annealed at $100^{\circ} \mathrm{C}$ for $5 \mathrm{~min}$. From this figure, it can be seen that PVC is characterized by two peaks. The peak at $69.5^{\circ} \mathrm{C}$ is very close to the glass transition temperature as determined to be at $78.8^{\circ} \mathrm{C}$ by using Perkin-Elmer 7 series thermal analysis system operated at a scanning rate of $10^{\circ} \mathrm{Cmin}^{-1}$, and thus is related to micro-Brownian motion of chain segments. The high amplitude and high conductivity of PVC at this temperature have been explained not only from the rotation of $\mathrm{C}-\mathrm{Cl}$ dipolar entities but also to some extent from the migration of ionic charge carriers. ${ }^{8} \mathrm{~A}$ very broad peak appeared at $-90.0^{\circ} \mathrm{C}$ is the $\beta$-transition,

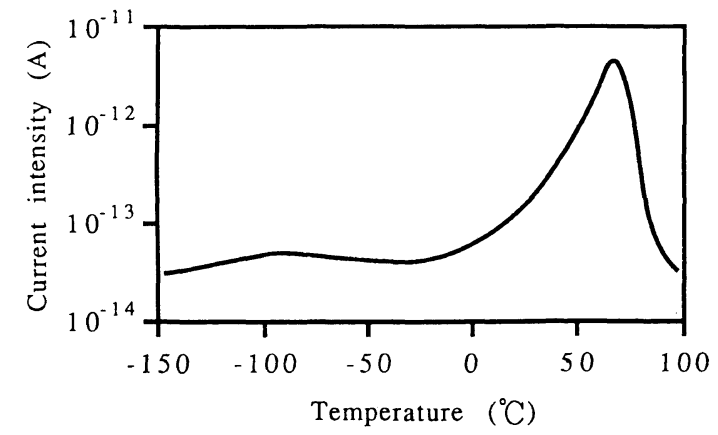

(a)

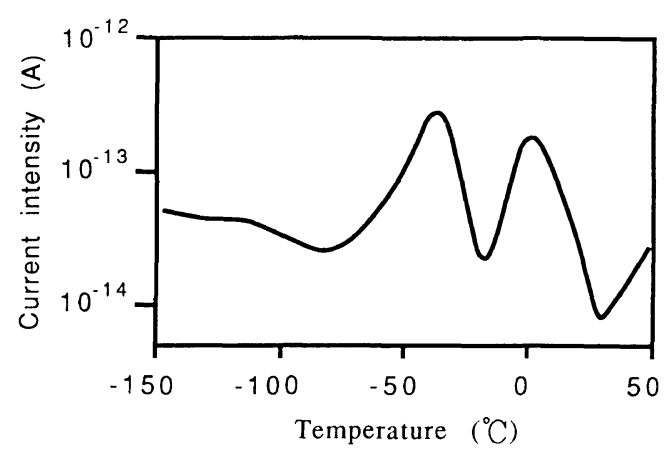

(b)

Figure 1. TSC global spectra of (a) PVC and (b) PEMMA. Poling conditions: (a) $T_{\mathrm{p}}=75^{\circ} \mathrm{C}, E_{\mathrm{p}}=200 \mathrm{kV}$ $\mathrm{m}^{-1}$ and $t_{\mathrm{p}}=2 \mathrm{~min}$. (b) $T_{\mathrm{p}}=0^{\circ} \mathrm{C}, E_{\mathrm{p}}=200 \mathrm{kVm}^{-1}$ and $t_{\mathrm{p}}=2 \mathrm{~min}$.

whose complex nature has been reported by del Val. ${ }^{9}$ Figure 1(b) shows the TSC spectrum of PEMMA. The peak at $-36.0^{\circ} \mathrm{C}$ has been characterized previously as the glass transition, while the peaks at $-120.0^{\circ} \mathrm{C}$ and $5.0^{\circ} \mathrm{C}$, as polyethylene local motion and space charge, respectively. ${ }^{10}$

\section{Blends}

The TSC global spectra of PVC/PEMMA blends show somewhat different patterns compared to their original polymers as illustrated in Figures 2(a) and 2(b). All polymer blends show three group of peaks: VM5 shows its peaks at $-72.0,-25.4$, and $63.4^{\circ} \mathrm{C}$; VM10, $-55.8,-3.4$, and $72.8^{\circ} \mathrm{C}$. The peaks observed for the all samples are listed in Table I.

From Figures 1 and 2, it is very clear that high temperature peaks in the global spectra 


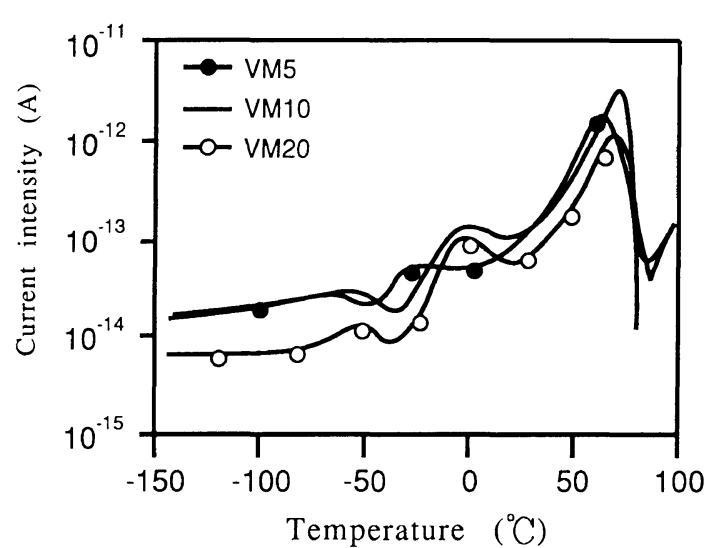

(a)

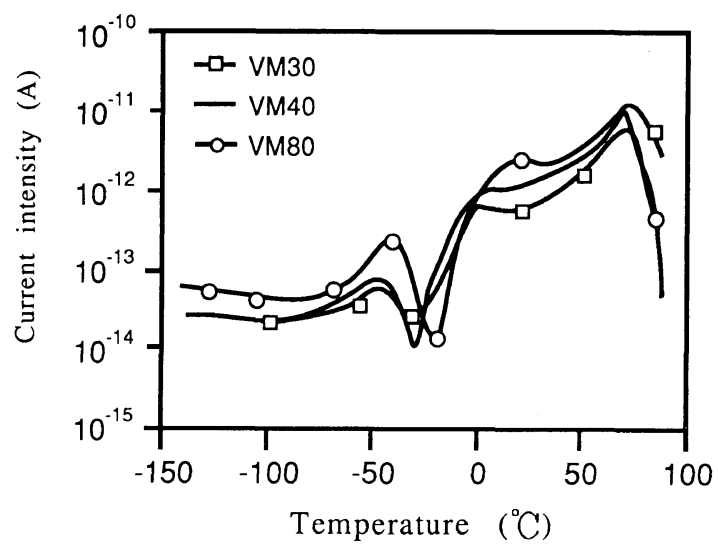

(b)

Figure 2. TSC global spectra of the PVC/PEMMA blends polarized at $75^{\circ} \mathrm{C}$ with $E_{\mathrm{p}}=200 \mathrm{kV} \mathrm{m}^{-1}$ and $t_{\mathrm{p}}=$ $2 \mathrm{~min}$.

of the blends correspond to the glass transition region of PVC. The addition of $5 \mathrm{wt} \%$ of PEMMA into PVC shifts the peak from $69.5^{\circ} \mathrm{C}$ to $63.4^{\circ} \mathrm{C}$ indicating that a small amount of PEMMA is dispersed in the PVC matrix. Further increase in the PEMMA content has no significant effect on the glass transition point of PVC-rich phase, indicating general immiscibility of the pair.

The PEMMA has a space charge at $5.0^{\circ} \mathrm{C}$ (see Figure 1(b)). The intermediate temperature peaks in the spectrum of the blends may thus be also generated by the space charge. To ensure if these are correct, the dependence of
Table I. Results of global TSC spectra for PVC, PEMMA, and their blends ${ }^{a}$

\begin{tabular}{lccc}
\hline \multirow{2}{*}{ Sample } & \multicolumn{3}{c}{ Peak temperature $\left({ }^{\circ} \mathrm{C}\right)$} \\
\cline { 2 - 4 } & Low & Intermediate & High \\
\hline VM5 & -72.0 & -25.4 & 63.4 \\
VM10 & -55.8 & -3.4 & 72.8 \\
VM20 & -52.6 & -1.4 & 68.1 \\
VM30 & -45.8 & 0.3 & 71.1 \\
VM40 & -44.1 & 3.0 & 71.0 \\
VM80 & -39.9 & 20.3 & 65.6 \\
PVC $^{\mathrm{b}}$ & -90.0 & - & 69.5 \\
PEMMA $^{\mathrm{c}}$ & -120.0 & -36.0 & 5.0 \\
\hline
\end{tabular}

a Polarization conditions: All the polymer blends were polarized at $75^{\circ} \mathrm{C}$ with $E_{\mathrm{p}}=200 \mathrm{kV} \mathrm{m}^{-1}$ for 2 min after aged $5 \mathrm{~min}$ at $100^{\circ} \mathrm{C}$.

b Without aging.

c PEMMA was polarized at $0^{\circ} \mathrm{C}$ for $2 \mathrm{~min}$ with $E_{\mathrm{p}}=$ $200 \mathrm{kV} \mathrm{m}^{-1}$.

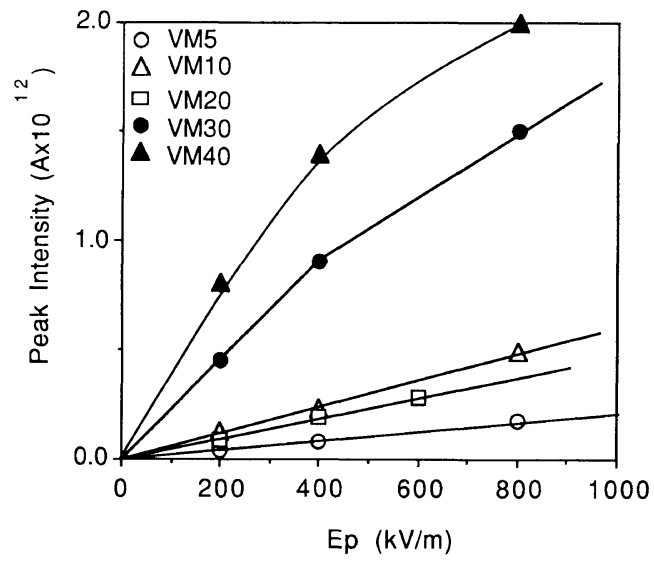

Figure 3. Dependence of peak intensity on the poling field $E_{\mathrm{p}}$ for the intermediate temperature peaks of $\mathrm{PVC} /$ PEMMA.

peak intensity on the poling field was investigated. Plotted in Figure 3 are results for the intermediate temperature peaks of the blends. The poling field is varied from $200 \mathrm{kV} \mathrm{m}^{-1}$ to $800 \mathrm{kV} \mathrm{m}^{-1}$, and the peak intensities of VM5, VM10, and VM20 increase linearly with the poling field. In contrast, the peak intensity shows a curvature when the poling field exceeds $400 \mathrm{kVm}^{-1}$ for VM30 and VM40. Therefore it is very clear that the intermediate 
Table II. Enthalpy of activation obtained at poling temperatures of $-10,0$, and $10^{\circ} \mathrm{C}$ for VM20 and VM40

\begin{tabular}{lccc}
\hline & \multicolumn{3}{c}{ Enthalpy of activation } \\
\cline { 2 - 4 } Sample & \multicolumn{3}{c}{$\mathrm{kcal} \mathrm{mol}^{-1}$} \\
& $-10^{\circ} \mathrm{C}$ & $0^{\circ} \mathrm{C}$ & $10^{\circ} \mathrm{C}$ \\
\cline { 2 - 4 } & & 26.58 & 25.74 \\
VM40 & 24.91 & 27.05 & 26.57 \\
VM20 & 27.77 & & \\
\hline
\end{tabular}

temperature peak results from space charge. Another way to differentiate the dipole relaxation mechanism from space charge is to measure TSC global spectra by relaxation map analysis. If a peak is generated from a space charge, the same enthalpy of activation should be observed in the measurement of RMA acrossing the TSC spectrum. ${ }^{11}$ The RMA results for VM20 and VM40 are listed in Table II. From Table II, it is noted that the values of the enthalpy of activation obtained at the poling temperature of $-10,0$, and $10^{\circ} \mathrm{C}$ are very similar for VM20 or VM40. The RMA results and those of the TSC strongly indicate that the intermediate temperature peaks arise from space charge.

In the study of TSC global spectra of the present blends, current intensity increases with the addition of PEMMA into PVC. These phenomena may be explained by poor miscibility between PVC and PEMMA. In the polarization of polymer blends, interfaces generated between the two immiscible matrix polymers are likely to store the charge. ${ }^{12}$ When the temperature is increased in the measurement of dipole relaxation, the stored charge is released. As a consequence, current intensity varies with the blend ratios.

In Figure 4 is illustrated the dependence of peak intensity on the poling field for the low temperature peaks of PVC/PEMMA blends. From Figure 4, it is obvious that peak intensity increases linearly with the poling field. These results indicate that low temperature peaks

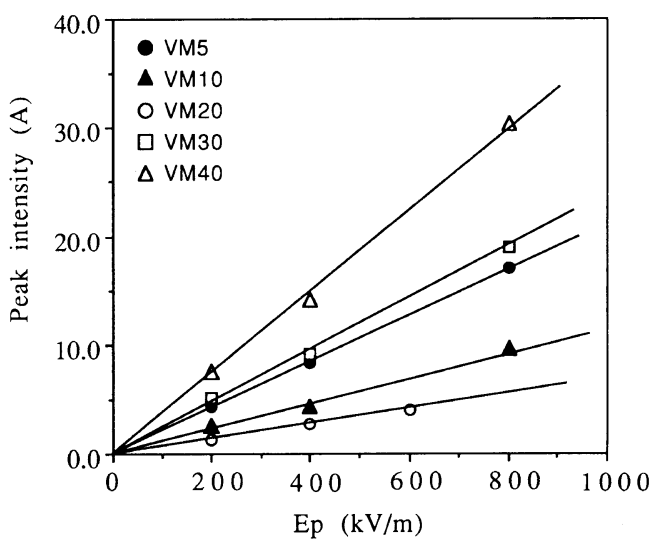

Figure 4. Dependence of peak intensity on the poling field $E_{\mathrm{p}}$ for the low temperature peaks of PVC/PEMMA.

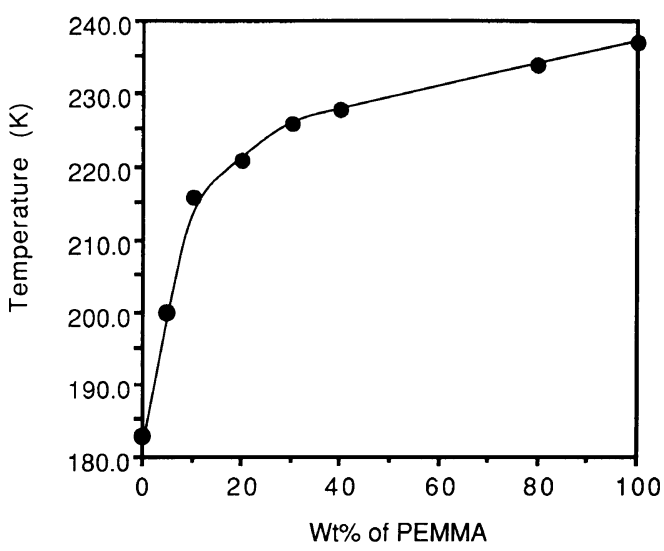

Figure 5. Relationship between PEMMA content and peak temperature for the low temperature peaks generated between the $\beta$-transition of PVC and $\alpha$-transition of PEMMA.

originate from the dipole orientation of polymer blends.

In Figure 5, the dependence of the peak temperature on the content of PEMMA is shown for the low temperature peak. The shift of this peak is most apparent up to $20 \mathrm{wt} \%$ of PEMMA. Some interactions may thus occur between PVC and PEMMA. Polyethylene is highly immiscible with PVC; the present results indicate that the copolymerization of methyl methacrylate into PE improves its compatibility with PVC. In the TSC spectra of 
PEMMA, a local motion of polyethylene segment appeared at $-120^{\circ} \mathrm{C}$ indicating that the MMA segment is not randomly distributed in the ethylene segment. ${ }^{10}$ Therefore, there may exist some MMA short segments in the poly(ethylene-co-methyl methacrylate). In the blending of PVC and PEMMA, these short MMA segments interact with the short PVC segment (that is the $\beta$-transition of PVC) through the polar ketone group of MMA with the tertiary hydrogen of PVC. As a consequence, a significant shift of the low temperature peak from $T_{\mathrm{g}}\left(=-36^{\circ} \mathrm{C}\right)$ of PEMMA is observed in Figure 5.

\section{Relaxation Map Analysis}

The Low-Temperature Peak

To obtain more detailed information on the TSC global spectra, low temperature peaks

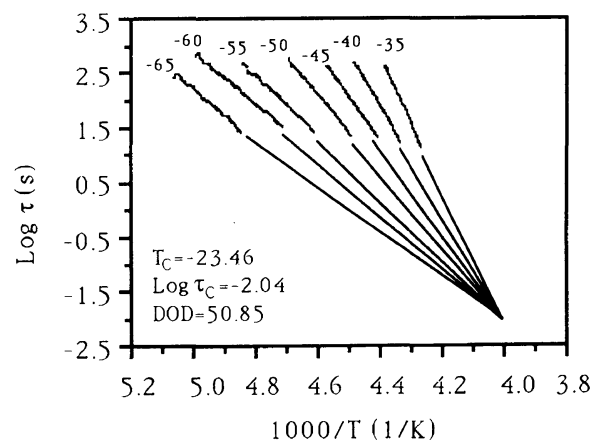

Figure 6. Compensation search for the relaxation map analysis results of VM80. The single lines correspond to various polarization temperature $\left(T_{\mathrm{p}}\right)$ from -65 to $-35^{\circ} \mathrm{C}$.

Table III. RMA results for low temperature peaks of PVC/PEMMA blends ${ }^{\mathrm{a}}$

\begin{tabular}{lccc}
\hline \multicolumn{1}{c}{ Sample } & $T_{\mathrm{c}} /{ }^{\circ} \mathrm{C}$ & $\log \tau_{\mathrm{c}} / \mathrm{s}$ & $\mathrm{DOD} / \mathrm{cal} \mathrm{K}^{-1}$ \\
\hline PVC $^{1}$ & -64.88 & -4.77 & 62.79 \\
VM10 & -26.52 & -1.89 & 50.18 \\
VM20 & -25.50 & -0.44 & 48.08 \\
VM30 & -24.68 & -1.21 & 47.01 \\
VM40 & -26.33 & -1.24 & 47.19 \\
VM80 & -23.46 & -2.04 & 50.85 \\
PEMMA & -16.41 & -1.46 & 48.12 \\
\hline
\end{tabular}

a Results were obtained with poling temperature at -70 , -80 , and $-90^{\circ} \mathrm{C}$. were analyzed by relaxation map analysis. In Figure 6 is plotted the results of VM80. From this figure, it is noted that these Arrhenius lines converge into one point. As described in the previous section, the critical temperature $T_{\mathrm{c}}$, relaxation time $\tau_{c}$ and degree-of-disorder (DOD) can be obtained through the compensation law. In Table III are listed the RMA results of the low temperature peaks of PVC/ PEMMA. From this table, one can observe that the addition of $5 \mathrm{wt} \%$ of PEMMA into PVC increases the $T_{\mathrm{c}}$ and $\tau_{\mathrm{c}}$, while it decreases the degree-of-disorder. The critical temperature is related to the maximum number of cooperative movement ${ }^{13}$; a higher $T_{\mathrm{c}}$ means more cooperative segmental motion. Therefore, molecular motion in the blends involves larger number of segments than that in PVC. Interactions between PVC and PEMMA not only drastically limit the movement of PVC segments which cause decrease of DOD, but also increase the relaxation time. However, although $T_{\mathrm{c}}$ and DOD vary little for PEMMA content of $20 \%$ to $80 \mathrm{wt} \%, \tau_{\mathrm{c}}$ changes remarkably from PVC to VM5 and slightly levels off from VM20 to VM40. This is consistent with the TSC results for blends where the maximum interaction is identified at an PEMMA level of $20 \mathrm{wt} \%$.

\section{The High-Temperature Peak}

In Table IV are also listed the RMA results of peaks found in the glass transition temperature range of PVC. For the sample of VM80 which has high PEMMA content up to $80 \mathrm{wt} \%$, it was very difficult to obtain RMA spectra at the glass transition temperature of

Table IV. RMA results for high temperature peaks of PVC/PEMMA blends

\begin{tabular}{lccc}
\hline Sample & $T_{\mathrm{c}} /{ }^{\circ} \mathrm{C}$ & $\log \tau_{\mathrm{c}} / \mathrm{s}$ & $\mathrm{DOD} / \mathrm{cal} \mathrm{K}^{-1}$ \\
\hline PVC & 76.48 & 0.19 & 39.88 \\
VM5 & 72.29 & 0.26 & 39.61 \\
VM20 & 72.94 & 0.69 & 37.63 \\
VM30 & 73.65 & 0.94 & 39.46 \\
VM40 & 76.06 & 0.72 & 37.48 \\
\hline
\end{tabular}




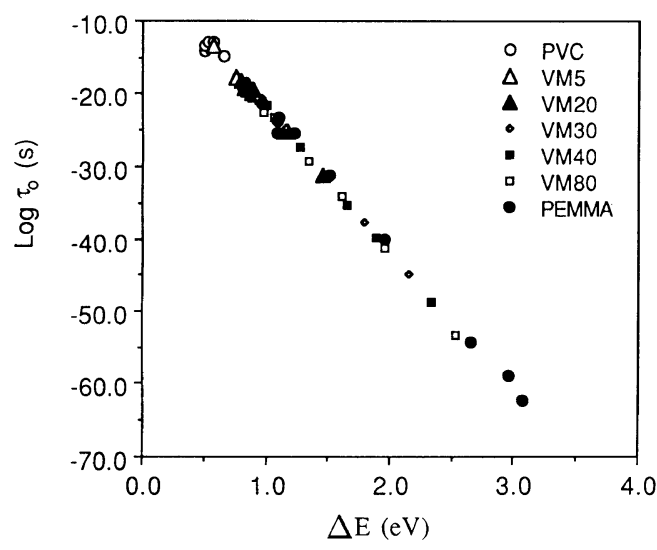

Figure 7. $\log \tau_{\mathrm{o}} v s$. activation energy $\Delta E$ diagram for the low temperature peaks generated between $\beta$-transition of PVC and $\alpha$-transition of PEMMA.

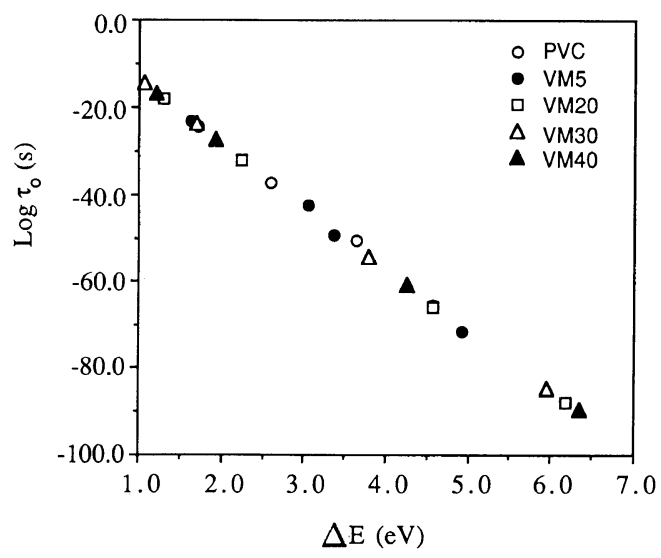

Figure 8. $\log \tau_{0} v s$. activation energy $\Delta E$ diagram for the high temperature peaks of PVC/PEMMA.

PVC, because PEMMA has a melting point at 53. $0^{\circ} \mathrm{C}$. From Table 4, it is also noted that the critical temperature and degree-of-disorder of PVC and PVC/PEMMA systems do not show much discrepancy. These results indicate that interactions between the polar group of MMA and tertiary hydrogen of PVC alter the relaxation time.

In Figures 7 and 8 are plotted relationships between the relaxation time and activation energy for the low temperature peaks of PVC/ PEMMA and peaks in the glass transition temperature range of PVC, respectively. From
Figure 7 , it can be seen that the activation energy has a linear relationship with relaxation time, corroborating the existence of compensation law. ${ }^{9}$ In this figure, it is observed that activation energy and relaxation time for the sub- $T_{\mathrm{g}}$ of PVC are very small. The addition of PEMMA into PVC slightly enlarges the activation energy as well as the distribution of relaxation time. Further addition of PEMMA increases these two factors and moves them close to those of PEMMA homopolymer. In Figure 8, the relationship between the relaxation time and activation energy is still well represented by a straight line. However, it is noted that PVC has low relaxation time and low activation energy less than $4 \mathrm{eV}$. The Addition of PEMMA into PVC not only decreases the relaxation time but also increases the activation energy to $6.5 \mathrm{eV}$ for VM40. The high activation energy and low relaxation time may be explained only in terms of cooperative motion corresponding to conformational change. ${ }^{13}$

\section{CONCLUSION}

1) The TSC global spectra of the PVC/ PEMMA blends showed three groups of peaks. The highest temperature peaks are located in the glass transition range of PVC. The intermediate temperature peaks arise from the space charge. The lowest temperature peaks were found between the $\beta$-transition of PVC and glass transition of PEMMA. Some interactions between the short chain segments of PVC and main chain segments of PEMMA occur. The maximum interaction appears at the PEMMA content of $20 \mathrm{wt} \%$.

2) The critical temperature at the compensation point and degree-of-disorder determined by RMA method remained almost constant irrespective of PEMMA content in the system, while the relaxation time significantly changes.

3) The addition of PEMMA into PVC not only decreases the relaxation time but also 
increases the activation energy. This is reasonably explained in terms of cooperative motions corresponding to conformational change.

\section{REFERENCES}

1. O. Ichii, Polym. Digest, 53, 4 (1988).

2. J. Oshima and I. Sasaki, Polym. News, 16, 198 (1991).

3. Y. Nakamura, K. Mori, and H. Nishina, J. Jpn. Adhesion Soc., 21(3), 95 (1985).

4. H. J. Busscher, W. Hoogsteen, L. Dijkema, G. A. Sawatsky, A. W. J. van Pelt, H. P. de Jong, G. Challa, and J. Arends, Polym. Commun., 26(8), 252 (1985).

5. C. Tremblay and R. E. Prud'homme, J. Polym. Sci.,
Polym. Phys. Ed., 22, 1857 (1984).

6. L. M. Robeson and J. E. McGrath, Polym. Eng. Sci., 17(5), 300 (1977).

7. J. P. Ibar, Polym. Eng. Sci., 31(20), 1467 (1991).

8. J. Vanderschueren, A. Janssens, M. Ladang, and J. Niezette, Polymer, 23, 395 (1982).

9. J. J. del Val, A. Alegria, J. Colmenero, and C. Lacabanne, J. Appl. Phys., 59(11), 3829 (1986).

10. S. I. Chen, J. Mater. Sci., in press.

11. A. Gourari, M. Bendaoud, C. Lacabanne, and R. F. Boyer, J. Polym. Sci., Polym. Phys. Ed., 23, 889 (1985).

12. J. Van Turnhout, in "Electrets," G. M. Sessler, Ed., Springer-Verlag, Berlin, 1980, p 158.

13. J. J. del Val, A. Alegria, J. Colmenero, and J. M. Barandiaran, Polymer, 27, 1771 (1986). 